\title{
FACTORS AFFECTING THE ELECTROSYNTHESIS AND PROPERTIES OF POLYANIIINE
}

\author{
R.M.G. RAJAPAKSE and L.P.P. LANKESHWARA \\ Department of Chemistry, University of Peradeniya, Peradeniya.
}

(Received : 02 June 1994; accepted: 10 October 1994)

\begin{abstract}
Aniline was polymerized to yield polyaniline by potentiostatic and potential cycling methods. Potentiostatic polymerization required at least $+0.60 \mathrm{~V}$ with respect to a saturated calomel electrode (SCE) and in the latter case the potential was cycled between $-0.1 \mathrm{~V}$ and $+0.8 \mathrm{~V}$ wrt SCE. Polyaniline films prepared from solutions having $\mathrm{pH}$ values greater than 3 were insulators, but those prepared in strong acidic media $(\mathrm{pH}<3)$ had potential dependent conductivity. These films can be switched reversibly from a conducting state to a non-conducting redox state by cycling the potential within the range of solvent limits. However, the application of a very high positive potential (ca. $>0: 8 \mathrm{~V} \mathrm{vs}$ SCE) in the absence of the monomer resulted in the destruction of the polymer. The background electrolyte had a decisive effect on the conductivity of the material. The change in potential of polyaniline resulted in the change in colour, i.e. polyaniline exhibited electrochromic properties. The colour of the polymer depends on various factors such as potential, $\mathrm{pH}$, type of the background electrolyte etc. Among the various polymers studied, $\mathrm{N}$-alkyl derivatives of polyaniline exhibited intense colours and fast switching times.
\end{abstract}

Key words: Polyaniline, electropolymerization, conductivity, electrochromicity

\section{INTRODUCTION}

Polymers have been traditionally used as insulators. However, there exists a class of polymers which has the ability to conduct electricity under certain conditions. Members of this class possess conductivities ranging from that of a semiconductor to a metal. Some of these compounds may be made to conduct better than copper at room temperature. ${ }^{1}$ Such polymers are called conducting polymers. By combining the remarkable properties of polymers such as inertness, durability, flexibility, lightweight with conductivity, material that may have many technical applications such as in electrode of batteries, ${ }^{2}$ as electrochromic devices, information memories, artificial nerves in bio-medicine, anticorrosives, electrocatalysers etc.can be prepared..$^{1-3}$ Such compounds have been investigated for their applicability in these areas. However, further basic research is required to circumvent the problems associated with their industrial applications. Polyaniline is a conducting polymer that is readily prepared from aqueous solutions and the conducting form is stable in air and water. ${ }^{4}$ Its growth conditions and properties have been extensively studied. ${ }^{5-10}$ According to Ginder et al. ${ }^{11}$ polyaniline exists in different, possibly coexisting forms which include benzanoid and chinoid (quinanoid) rings, free amines, free imines, protonic amines and protonic imines. In this study, we describe the preparation, characterization and electrochromic properties of polyaniline and its derivatives using cyclic voltammetry. Our results show that the $\mathrm{pH}$ of the medium is a decisive factor contributing to conductivity and the counter ions in the solution influence the structure and hence the properties of polyaniline and its derivatives. 


\section{METHODS AND MATERIALS}

Chemicals and apparatus: Chemicals were of Analar grade (BDH and Aldrich, UK) used without further purification, except aniline which was distilled at $182^{\circ} \mathrm{C}$ and stored at $4^{\circ} \mathrm{C}$. Distilled water was also used in our experiments. Electrochemical studies were carried out using an electrochemical set up purchased from Oxford Electrodes. Cyclic voltammograms and other electrochemical signals were recorded on a YEW MODEL $3022 \mathrm{X}-\mathrm{Y}$ Chart recorder. All potentials given are with respect to a SCE.

Synthesis of Polyaniline : In a typical experiment, $1.0 \mathrm{~cm}^{3}$ of distilled aniline was added to a solution of $0.1 \mathrm{~mol} \mathrm{dm}^{-3}$ background electrolyte, $\mathrm{Na}_{\mathrm{n}} \mathrm{X}$, where $\mathrm{n}=1$ for $\mathrm{X}=\mathrm{ClO}_{4}, \mathrm{Cl}, \mathrm{Br}, \mathrm{NO}_{3}$ and $\mathrm{n}=2$ for $\mathrm{X}=\mathrm{SO}_{4}$ ) and the $\mathrm{pH}$ adjusted using the corresponding acid $\mathrm{H}_{\mathrm{n}} \mathrm{X}$. The solution was transferred to a two compartment cell consisting of a working electrode (Pt disc or Antimony doped tin oxide glass), an auxilliary electrode ( $\mathrm{Pt}$ gauze) and a reference electrode (aq. $\mathrm{KCl} \mathrm{SCE}$ ); the solution was next purged with $\mathrm{O}_{2}$ free $\mathrm{N}_{2}$ gas for $30 \mathrm{~min}$. The flow of $\mathrm{N}_{2}$ gas was kept above the solution during the experiment to avoid diffusion of oxygen back into the solution. The auxilliary electrode was kept in the-second compartment of the cell which was separated from the first part by a porous plug. The working electrode was held at $0.7 \mathrm{~V}$ in potentiostatic experiments. The potential of the working electrode was cycled between 0 and $0.7 \mathrm{~V}$ during potentiodynamic process. The instrumentation employed in this work is shown in Figure 1. A smooth layer of polyaniline was deposited on the working electrode as a result.

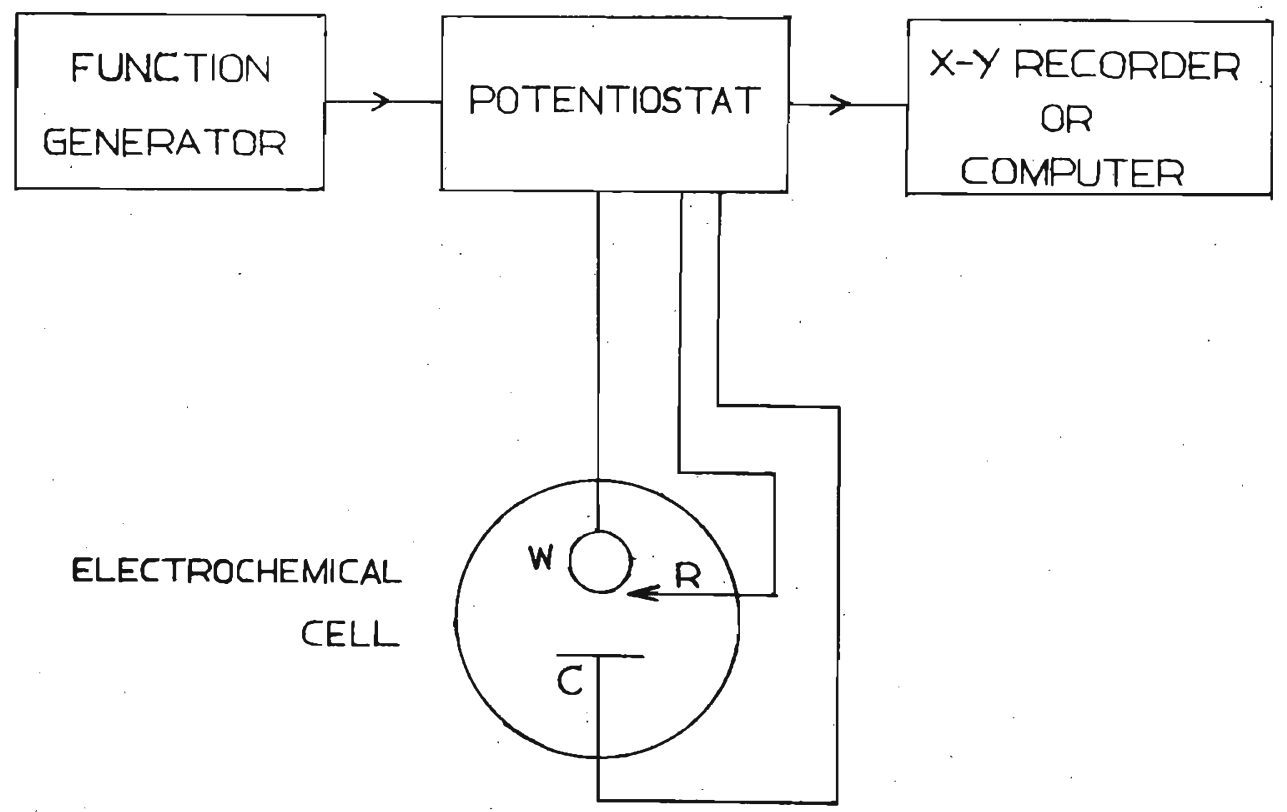

Figure 1: Instrumentation used in the electrosynthesis of polyaniline $\mathbf{W}, \mathbf{R} \& \mathbf{C}=$ working, reference and counter electrode respectively. 


\section{RESULTS}

Figure 2 shows the current density versus time responses at various applied potentials for the polymerization of aniline from a deoxygenated solution containing $0.1 \mathrm{~mol} \mathrm{dm}^{-3} \mathrm{NaCl}$ at $\mathrm{pH} 1$. No detectable currents were observed if the applied potential was below $0.4 \mathrm{~V}$. (curves a,b and c) and consequently no polymer coating was observed. When $0.4 \mathrm{~V}$ was applied to the working electrode we observed a very slow growth of a polymer on the electrode. The polymer thus grown was non-conducting and hence the current decreased with time due to the insulation of the electrode. Increase in potential resulted in an increased rate of polymerization as seen from curves $e$ and $f$; however, polymers formed at these potentials wore also non-conducting. An interesting behaviour was observed at $0.6 \mathrm{~V}$ in which the current decreased initially but with time it began to increase slowly (curve g). Further increase in potential enhanced the rate of polymerization. The cycling of the potential between $-0.1 \mathrm{~V}$ and $0.8 \mathrm{~V}$ also resulted in the deposition of the polymer on the electrode. The currents generated enhanced considerably in the successive cycles as can be seen from Figure 3. Figure 4 depicts the cyclic voltammograms of polyaniline at a scan rate of $20 \mathrm{mV} \mathrm{s}^{-1}$ grown from a deoxygenated solution containing $0.1 \mathrm{~mol} \mathrm{dm}^{-3} \mathrm{NaCl}(\mathrm{aq})$ at various $\mathrm{pH}$ values. The conductivity of the polymer was lost if the $\mathrm{pH}$ of the medium is above ca. 3. Decrease of $\mathrm{pH}$ of the solution increased growth rate and conductivity of the polymer. Polyanilines grown from solutions of the same strength and the other conditions but with different anions, had different physical, chemical and electrochemical properties. As Figure 5 depicts, the cyclic voltammograms of polyaniline obtained from different background electrolytes have different behaviours. The peak positions and peak currents obtained in these experiments are listed in Table 1. Table 2 lists the colours of polyaniline at various applied potentials.

Table 1: Peak potentials and currents obtained from cyclic voltammograms of polyaniline in various background electrolytes at pH 2.

\begin{tabular}{lcccc}
\hline Anion & \multicolumn{2}{c}{ Anodic peak 1 } & \multicolumn{2}{c}{ Cathodic peak 1 } \\
& $\begin{array}{c}\text { Peak current } \\
(\mu \mathrm{A})\end{array}$ & $\begin{array}{c}\text { Peak potential } \\
(\mathrm{V})\end{array}$ & $\begin{array}{c}\text { Peak current } \\
(\mu \mathrm{A})\end{array}$ & $\begin{array}{c}\text { Peak potential } \\
(\mathrm{V})\end{array}$ \\
\hline $\mathrm{ClO}_{4}^{-}$ & 63.00 & 0.37 & 20.00 & 0.10 \\
$\mathrm{Cl}^{-}$ & 85.00 & 0.42 & 100.00 & 0.34 \\
$\mathrm{Br}^{-}$ & 2200.00 & 0.53 & 1550.00 & 0.31 \\
\hline
\end{tabular}




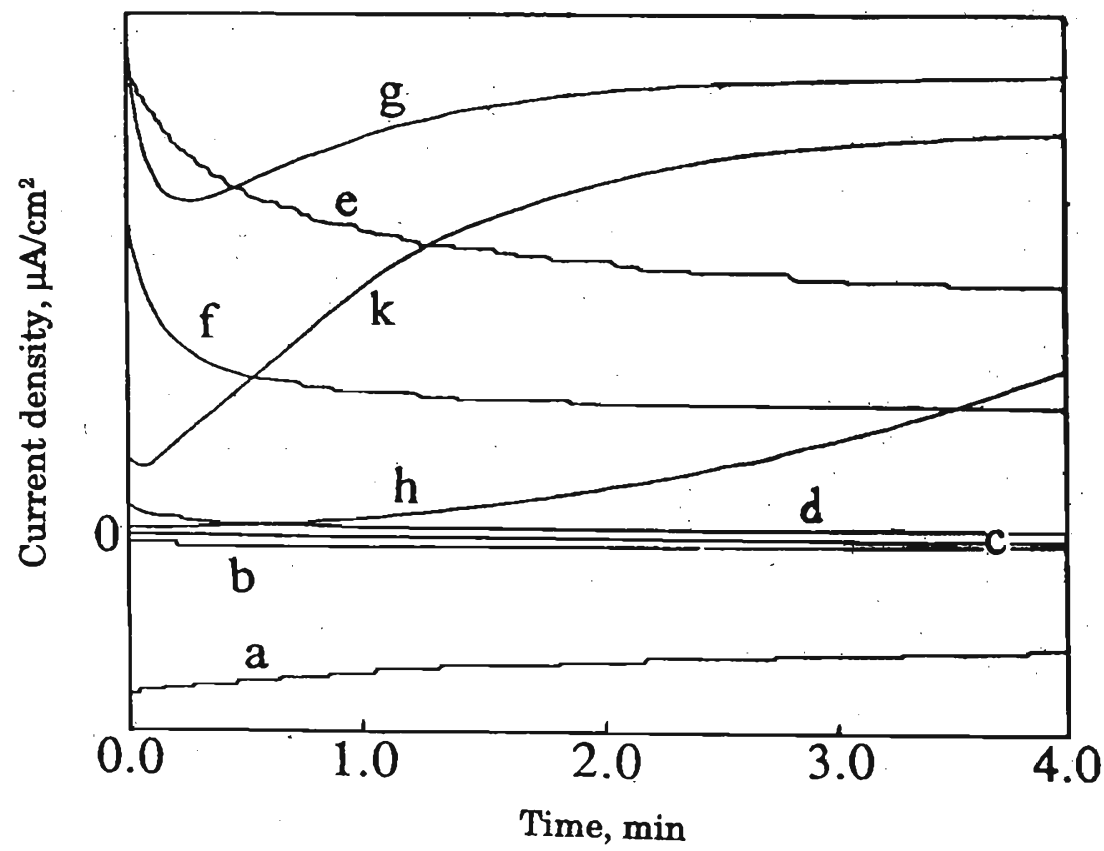

Figure 2: Plots of current density against time for the electropolymerization of aniline on platinum disc electrode from a degassed solution of $0.1 \mathrm{M} \mathrm{NaCl}$ at $\mathrm{pH} 1(\mathrm{HCl})$ at various applied potentials.

The applied potentials for curves $a, b, c, d, e, f, g, h, k$ are $0.1,0.2,0.3$, $0.4,0.5,0.55,0.6,0.7 .0 .8 \mathrm{~V}$ respectively.

The current densities per centimeter are different for the different curves.
a. $2.7 \mu \mathrm{A} \mathrm{cm}^{-2}$
b. $2.7 \mu \mathrm{A} \mathrm{cm}^{-2}$
d. $2.7 \mu \mathrm{A} \mathrm{cm}^{-2}$
e. $0.27 \mu \mathrm{A} \mathrm{cm}-2$
g. $0.67 \mu \mathrm{A} \mathrm{cm}^{-2}$
h. $675.67 \mu \mathrm{A} \mathrm{cm}^{-2}$
c. $2.7 \mu \mathrm{A} \mathrm{cm}^{-2}$
f. $0.67 \mu \mathrm{A} \mathrm{cm}^{-2}$
k. $1351.35 \mu \mathrm{A} \mathrm{cm}^{-2}$

Table 2: Electrochromic properties of polyaniline and poly-N-Methylaniline.

\begin{tabular}{lcl}
\hline Conducting polymer & $\begin{array}{c}\text { Potential/V } \\
\text { (wrt SCE) }\end{array}$ & Colour \\
\hline Polyaniline & +0.70 & Dark blue \\
& +0.20 & Greenish blue \\
& +0.10 & Green \\
& -0.40 & Light green \\
Poly-N-Methylaniline & -0.60 & Yellow \\
& +0.70 & Dark blue \\
& -0.70 & Dark yellow \\
\hline
\end{tabular}




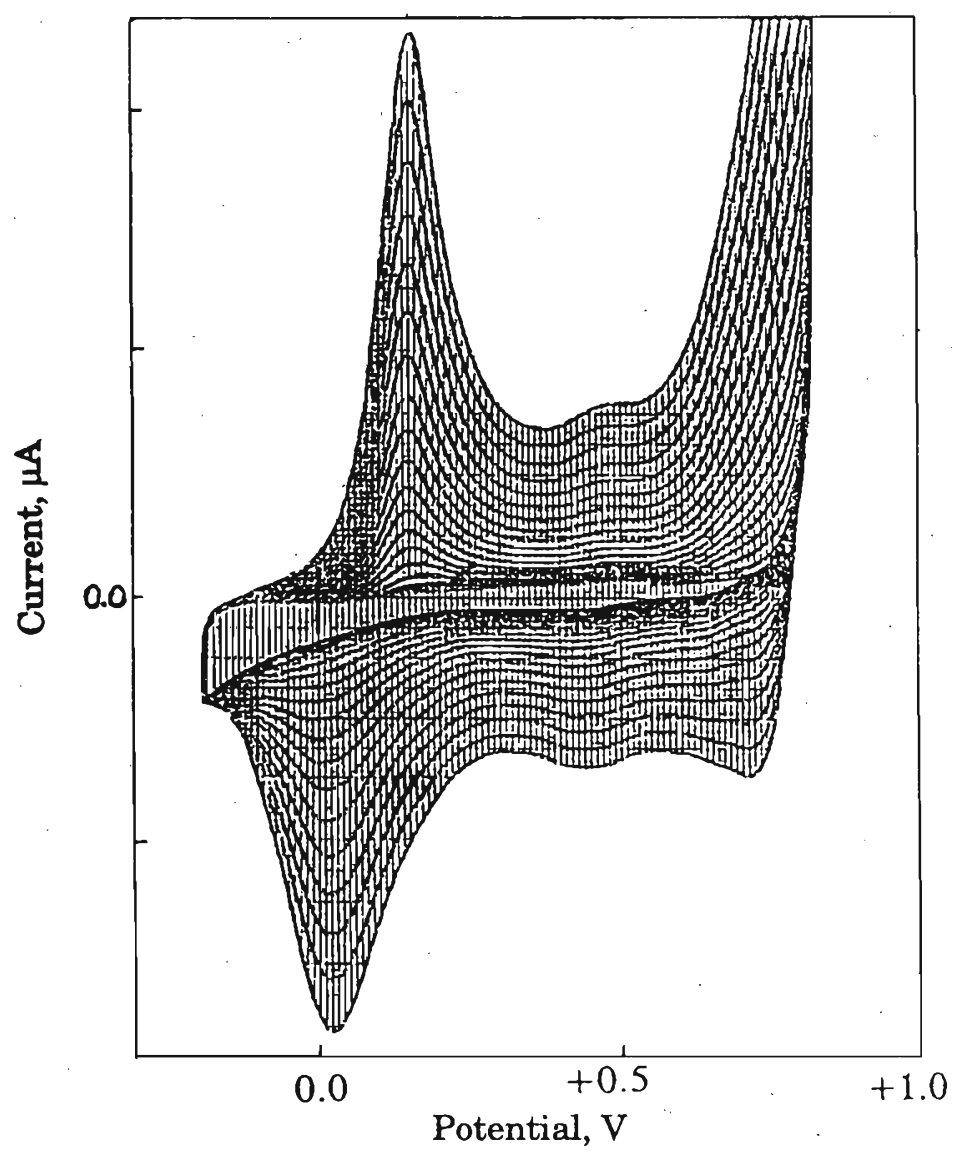

Figure 3: Cyclic voltammograms of polyaniline during the preparation in a deoxygenated solution containing $0.1 \mathrm{M} \mathrm{NaCl}$ at $\mathrm{pH} 1$ (HCl).

Scan rate: $20 \mathrm{mV} \mathrm{s}^{-1}$

$\mathrm{X} \Rightarrow 0.1 \mathrm{~V} / \mathrm{cm}$

Y. \& $50 \mu \mathrm{A} / \mathbf{c m}$

\section{DISCUSSION}

The effect of potential on the growth of polyaniline may be explained as follows. The polymer can only be electrosynthesized at sufficiently oxidizing potentials. In the cases depicted by curves $a, b$ and $c$, the applied potential is insufficient to oxidize the monomer. The potential of $0.6 \mathrm{~V}$ is sufficient to oxidize the monomer but only just sufficient to oxidize the polymer thus generated. Hence initially the polymer formed is non-conducting; however, as the oxidation of the polymer occurs slowly the electrode regains its conductivity with time. Further increase in potential enhances the rates of both polymerization and oxidation, resulting in the rapid growth of highly conducting polyaniline film on the working electrode. 


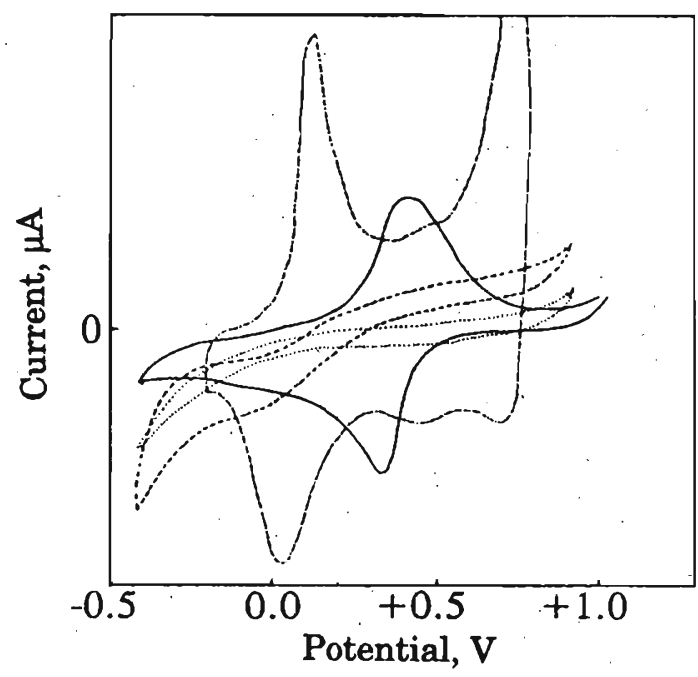

Figure 4: Cyclic voltammograms of polyaniline in $0.1 \mathrm{M} \mathrm{NaCl}$ at different $\mathrm{pH}$ values. Scan rate: $20 \mathrm{mV}$ s. $^{-1}$

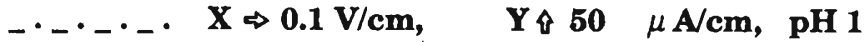

$$
\begin{aligned}
& \mathrm{X} \Rightarrow 0.1 \mathrm{~V} / \mathrm{cm}, \quad \mathrm{Y} \text { i } 25 \mu \mathrm{A} / \mathrm{cm}, \quad \text { pH } 2 \\
& \mathrm{X} \Rightarrow 0.1 \mathrm{~V} / \mathrm{cm}, \quad \mathrm{Y} \text { \& } 5 \mu \mathrm{A} / \mathrm{cm}, \quad \mathrm{pH} 4 \\
& \text {.................. X } \quad \mathrm{X} \Rightarrow 0.1 \mathrm{~V} / \mathrm{cm}, \quad \text { Y } 0.25 \mu \mathrm{A} / \mathrm{cm}, \quad \mathrm{pH} 7.5
\end{aligned}
$$

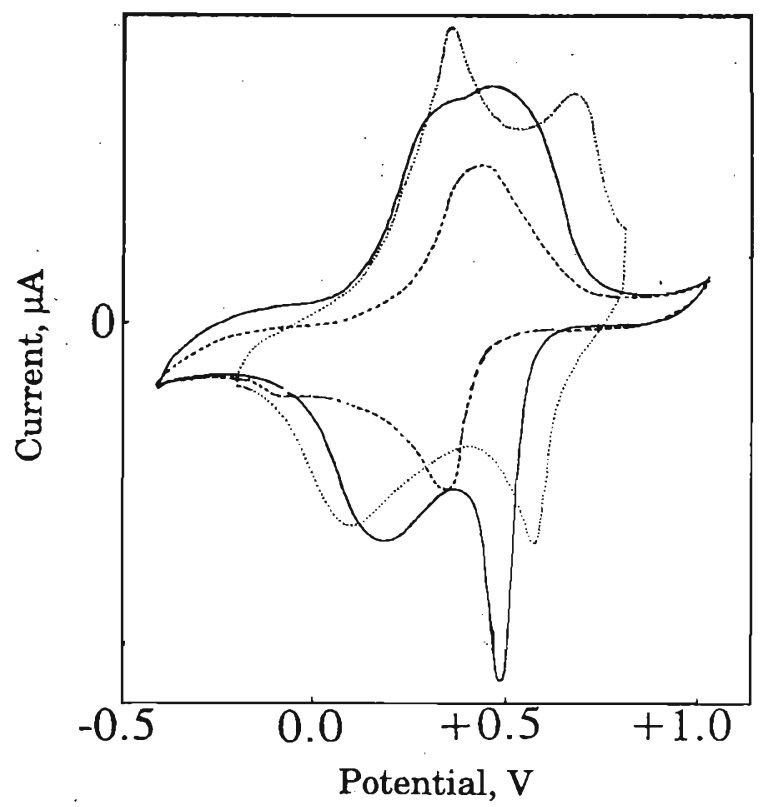

Figure 5: Cyclic voltammograms of polyaniline in different background electrolytes. Scan rate: $20 \mathrm{mV} \mathrm{s}^{-1}$

$$
\begin{aligned}
& \longrightarrow \mathrm{X} \Rightarrow 0.1 \mathrm{~V} / \mathrm{cm}, Y \text { Y } 25 \mu \mathrm{A} / \mathrm{cm}, 0.1 \mathrm{M} \mathrm{CH} \mathrm{CHOONa}_{3} \\
& \ldots . . . . . X \Rightarrow 0.1 \mathrm{~V} / \mathrm{cm}, Y \text { Y } 25 \mu \mathrm{A} / \mathrm{cm}, 0.1 \mathrm{M} \mathrm{NaCl} \\
& \ldots \ldots \ldots \ldots X \Rightarrow 0.1 \mathrm{~V} / \mathrm{cm}, Y \text { Y } 10 \mu \mathrm{A} / \mathrm{cm}, 0.1 \mathrm{M} \mathrm{NaClO}_{4}
\end{aligned}
$$


Electrodeposition of polyaniline can also be achieved by cycling the potential. This technique facilitates the partial or complete oxidation of the polymer film when it is at oxidizing potentials and reduction at reducing potentials. Since the polymer is grown only at oxidizing potentials, the currents generated in successive forward scans should increase as a result of oxidation of increased amounts of the polymer. This is in fact seen when the potential is cycled during poly 2 rization. The polymer can therefore be reversibly oxidized or reduced without structural damage. Note however, that if the potential is increased to a very high value $(\mathrm{ca}>0.8 \mathrm{~V}$ ) in the absence of the monomer the polymer undergoes destruction. The conductivity of the polymer is lost at $\mathrm{pH}>3$. Decrease of $\mathrm{pH}$ increased growth rate and conductivity. This result is consistent with that obtained for polyaniline grown from non-aqueous solutions. Therefore, at least a part of the amino groups in the polymer backbone should be protonated when the polymer is in its conducting state. Thus these results confirm the presence of both benzenoid and quinoid parts in the polymer and that the relative proportions of these two structural units determine the conductivity of the polymer. The general structure of polyaniline can therefore be written as:

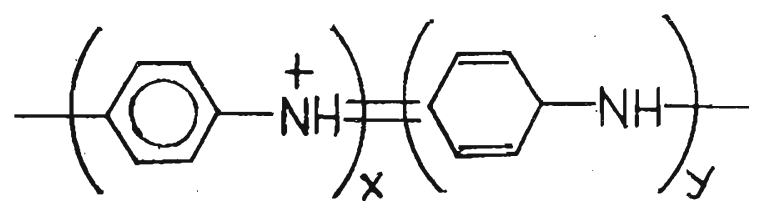

However, the sequence of the benzenoid and quinoid forms in the structure may vary depending on the conditions.

The fact that the polymer is conducting only at positive potentials suggests that the polymer backbone needs to be positively charged for conductivity. The overall electrical neutrality of the polymer is then obtained by taking anions into the polymer. Polyaniline grown from a solution containing polyanions and small cations does not show conductivity under any conditions. This is possibly due to the fact that the bulky polyanions cannot diffuse into the polymer and hence the oxidation of the polymer cannot be achieved without fragmentation even at very positive potentials. However, polyaniline grown from a solution of polycation chloride has a conductivity comparable to that of polyaniline grown from a $\mathrm{NaCl}$ solution of the same chloride concentration. ${ }^{12}$ This is clear evidence for the incorporation of the small anions into the polymer at its conducting state through the pores of the polymer. Anions that have a tendency to polarize, such as bromide, iodide, acetate are specifically adsorbed on the polymer structure. Those specifically adsorbed ions show sharp and symmetrical peaks in the cyclic voltammograms. The presence of specifically adsorbed organic molecules and ions on an electrode is particularly useful as anodes of fuel cells. Inert electrodes modified by conducting organic polymers thus have possible applications in electrocatalysis. The change of potential appears to affect the conductivity of 
polyaniline. This may be due to the changes of the structure undergone by the polymer at different applied potentials. The accompanied colour change of the material tends to support this view. Polyaniline is an electrochromic conducting polymer producing a spectrum of colours depending on the potential.

\section{Acknowledgement}

Financial support from NARESA (RG/92/C/04) is gratefully acknowledged. We thank Mr. P.H.S.S. Ariyapala for assistance and valuable suggestions.

\section{References}

1. Kaner R.B. \& MacDiarmid A.G. 988). Plastics that conduct electricity. Scientific American 258(2): 60-65.

2. Osaka T., Nakajima T., Shiota K. \& Momma T. (1991). Electroactive polyaniline film deposited from non-aqueous media. Journal of Electrochemical Society 138(10):2853-2858.

3. Dao Le.H., Guay J. \& Leclerc M. (1989). Poly(N-Aryanilines)-synthesis and spectroelectrochemistry. Synthetic Metals 29: E383-E388.

4. Dao L.H., Leclerc M., Guay J. \& Chevalier J.W. (1989). Synthesis and characterization of substituted polyanilines. Synthetic Metals 29: E377E382.

5. Tsakova V. \& Milchev A. (1991). Electrochemical formation and stability of polyaniline films. Electrochimica Acta 36(10):1579-1583.

6. Ofer D.,Crooks R.M. \& Wrighton M.S. (1990). Potential dependence of the conductivity of highly oxidized polythiophenes, polypyrroles and polyaniline: Finite windows of high conductivity. Journal of American Chemical Society 112(22):7869-7879.

7. Stilwell D.E. \& Park S.M. (1989). Degradation reaction kinetics of polyaniline studied by rotating ring disc electrode techniques. Journal of Electrochemical Society 136(3): 688-698.

8. Stilwell D.E. \& Park S.M. (1989). Degradation reaction kinetics of polyaniline studied by rotating ring disc electrode techniques. Journal of Electrochemical Society 136(3): 2498-2502.

9. Neoh K.G. \& Kang E.T. (1991). Structural study of polyaniline films in reprotonation/deprotonation cycles. Journal of Physical Chemistry 95(24): 10151-10156.

10. Wan M., Yang G., Zhu C. \& Bai C. (1992). Scanning tunnelling microscopy images of polyaniline. Thin Solid Films 208:153-155. 
11. Ginder J. M., Epstein A.J. \& MacDiarmid A.J. (1989). Electronic phenomena in polyaniline. Synthetic Metals 29: E395-E400.

12. Rajapakse R.M.G., Lankeshwara L.P.P. \& Careem M.A. (1994). Synthetic Metals In press. 